\title{
Spelling recognition and coding by poor readers*
}

\author{
JANE F. MACKWORTH \\ and NORMAN H. MACKWORTH \\ Stanford University, Stanford, Calif. 94305
}

Thirty good readers and 30 poor readers in Grade 10 (aged 15-17) were given a series of tests to determine individual profiles of difficulty. In one test, they were asked to judge whether a single printed word was spelled correctly or not, and in another they were asked to judge whether two printed words sounded the same or not. All the poor readers showed a marked difficulty in spelling recognition, while difficulty in coding into sound was related to the lowest scores on a reading test. The very poor readers also showed prolonged reaction in times. It was concluded that inadequate visual models of words in long-term memory are characteristic of poor readers, while those with the greatest difficulty also have trouble linking the written word to internal speech models.

Reading involves the translation of a written code into speech. To do this, the reader must have a clear long-term visual memory of written words, closely linked with the memorized speech patterns (J. Mackworth, 1972). If the visual record is inadequate, then there will be difficulty in "recognizing" or naming the word. Posner, Lewis, \& Conrad (1972) have emphasized that "different children may find their strengths in different subskills." These workers found that it takes longer to match written letters by name than by visual identity, and they argue that the visual process is an isolable subsystem. The spelling patterns regarded by Gibson (1965) as the primary units of reading can be matched visually faster than the same number of unrelated letters. Long ago, Cattell (1886) showed that words could be read almost as fast as individual letters when presented tachistoscopically. The visual system is well adapted for parallel processing.

Other workers have placed the emphasis in reading at the coding level or even at the comprehension level. Shankweiler \& Liberman (1972) have suggested that the major problem in learning to read lies in the multiple relationships between spelling and sound. The present study examines the two basic skills of reading: visual recognition of words and coding into sound. A previous study of 80 children in Grades 1 through 6 showed that the poor readers in each grade had no difficulty in recognizing that two words looked exactly alike, but they were less able to distinguish small differences between words. These young readers also had difficulty in coding words into sound, but by Grade 6 this coding difficulty had almost disappeared. ${ }^{1}$ The coding test was

*The authors were supported by the Scottish Rite Institute for Childhood A phasia and by Research Scientist Award K5-36, 447 from the National Institute of Mental Health. Request reprints from the Department of Psychology, Stanford University. Grateful thanks are due to the principal, staff, and students of the Palo Alto High School for their generous cooperation and encouragement. part of a battery of tests designed to determine the profile of difficulty demonstrated by each individual child. The tests ranged from eye-movement recordings during reading to comprehension tests. The coding test proved to be too easy for the high school students, so a new test was designed. Since visual comparisons of words had proved difficult for poor readers, part of the new test required the students to identify correct spelling of a word. S had to match the printed word with his stored visual image of that word to determine whether there was a discrepancy between the two.

\section{METHOD \\ Subjects}

The test was given to $60 \mathrm{Ss}$ in Grade 10 (aged 15-17). Thirty were in remedial reading classes, and 30 were regarded as normal readers. The poor readers were all below the 50 th percentile in the Gates-MacGinitie Reading Test, while the good readers were all above the 50 th percentile. The average age of the poor readers was slightly older than that of the good readers.

\section{Procedure}

The test consisted of two parts. In the first part, $\mathrm{S}$ was asked to say whether or not a particular word was spelled correctly. The words were shown one at a time on a screen, and $S$ indicated his decision by pressing one of two buttons. The word remained on view until S responded, and the duration of the display was recorded on an electric timer. Half of the 18 words were spelled wrongly, with one letter incorrect or omitted. In the second part of the test, there were 20 pairs of words, one pair being shown at a time. S was asked to decide whether or not the two words sounded the same (e.g., cruise-crews) or different (e.g., dairy-diary). There were 10 sound-alike pairs.

\section{RESULTS}

The relations between reading ability, error scores, and median reaction times were highly significant. First, Ss were ranked according to their percentile ranks on the vocabulary section of the Gates-MacGinitie Reading Test, and they were divided into four groups of $15 \mathrm{Ss}$ each. Table 1 shows the mean error scores and the averages of each S's median RT on the spelling test. Analysis of variance of total errors showed highly significant differences between groups $(\mathrm{F}=30.3$, df $=$ $3 / 56, p<.001)$. Figure 1 shows the mean errors for each group in relation to the mean percentile ranks for that group.

Table 1

Errors and Reaction Times by Grade 10 Ss on Spelling/Sound-Alike Test $(N=60)$

Group Percentiles on Gates MacGinitie Test

\begin{tabular}{lrrrc} 
& & $89-$ & $50-$ & Below \\
Errors & $90+$ & 60 & 30 & 30 \\
\hline Spelling (Maximum 18) & 2.9 & 4.5 & 6.6 & 9.2 \\
Sound-Alike (Maximum 20) & 2.0 & 3.0 & 4.8 & 6.8 \\
Reaction Times (Sec) & 2.7 & 2.7 & 3.6 & 5.8 \\
\hline
\end{tabular}




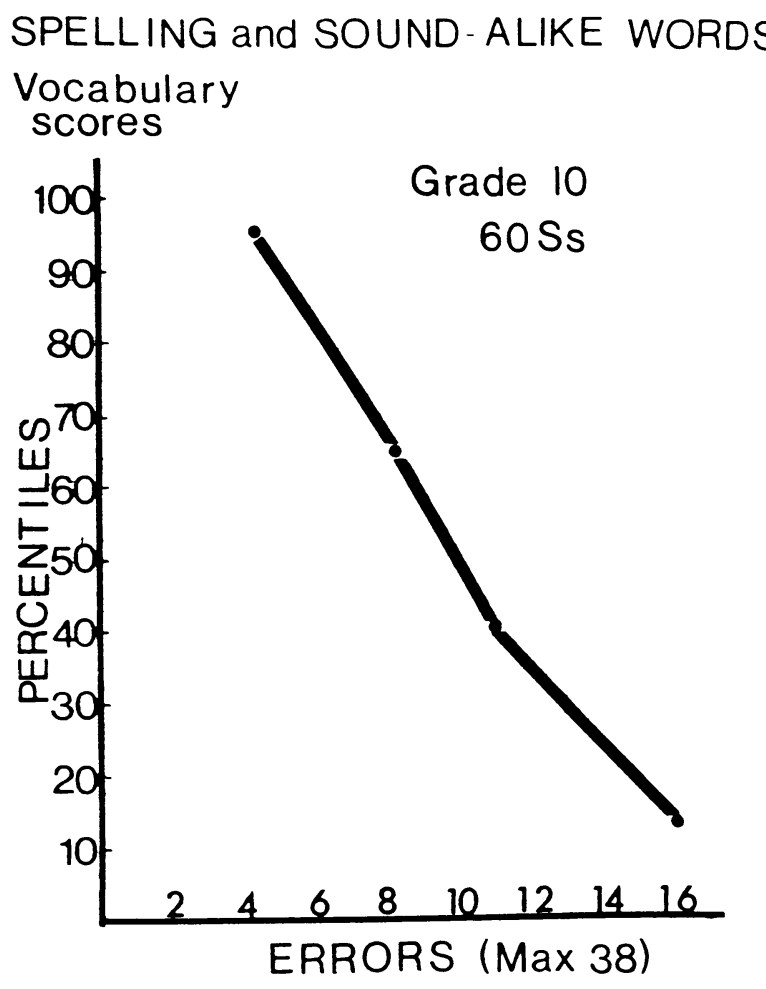

Fig. 1. The relation between vocabulary scores on the Gates-MacGinitie reading test and total errors on the spelling/sound-alike test.

The students were ranked by their total error scores, and also by the median RTs. The Spearman rank-order correlation coefficient (rho) for the relation between the Gates-MacGinitie percentile ranks and total error ranks was 0.78 . with a $t$ test value of $8.96 .(p<.001)$. The three rank orders were also correlated by Kendall's coefficient of concordance $(\mathrm{W}=0.61, \mathrm{p}<.01)$ (Downie $\&$ Heath. 1965). Thus, the error score was a good measure of reading ability, while the RTs were not quite as good. There was more overlap between the RTs for good and poor readers than there was with the error scores for the two groups.

Table 1 shows that the spelling recognition test was more difficult than the sound-alike part of the test. The worst readers actually achieved error scores on the spelling test that were higher than the chance level of 9 errors. Six of the poorest readers made from 10-14 errors on the 18 words. Only 4 of the 30 good readers made more than 6 errors on the spelling. while only 4 of the poor readers made less than 6 errors.

There were 3 girls and 12 bovs in the worst reading group. while in the other three groups there were 24 girls and 21 boys.

\section{DISCUSSION}

It is probable that. for young readers, the most difficult part of learning to read is learning the relationship between sight and sound of words. as Shankweiler \& Liberman reported (1972). However. the preliminary step involves the construction of a mental image of each word, so that the printed word can be matched with this mental image. This is recognition. Buswell (1959) emphasized that the problem in reading is to learn to recognize the risual symbols with accuracy and reasonable speed. A skilled reader has a precise mental image of each word, so that when he sees the word it immediately activates the sound. the speech motor programs, and the meaning of that word. Spelling recognition depends on such a precise mental picture: the writer often becomes aware that he has mispelled a word when he sees what he has written. It looks odd, and so he tries other letters until the word looks right; that is. it matches precisely his internal visual model.

The results suggest that the good reader has such precise visual models, while the poor reader has much less accurate models. This initial inadequacy in the reading process will interfere with all the later processes of coding and comprehension. Fuzzy word images will result in words being read incorrectly. The characteristic of visual intake is parallel processing. Several words can be taken in at a glance, though in fact the average adult reader seldom takes in more than two (Buswell, 1959). But, if the mental models are inaccurate, the parallel processing will be greatly slowed. Such a difficulty may also account for the increased response times shown by the very poor readers.

In conclusion, the data indicate that poor readers in Grade 10 have a poor long-term visual memory for words, so that they cannot recognize whether or not the words are spelled correctly. More severely impaired readers also have difficulty with coding unusual grapheme-phoneme relationships. Such problems must seriously interfere with comprehension.

\section{REFERENCES}

Buswell. G. T. The process of reading. The Reading Teacher. $1959,13,108-114$.

Cattell, J. McK. The time it takes to see and name objects. Mind. 1886, $11,63-65$.

Downie, N. M., \& Heath, R. W. Basic statistical methods. New York: Harper \& Row. 1965.

Gibson, E. J. Learning to read. Science. 1965, 148, 1066-1072. Mackworth, J. F. Some models of the reading process: Learners and skiller readers. Reading Research Quarterly. 1972, 8. 701-733.

Posner, M. I., Lewis. J. L.. \& Conrad, C. Component processes in reading: A performance analysis. In J. F. Kavanaugh and I. G. Mattingly (Eds.), Language by ear and by eye. Cambridge. Mattingly (Eds.), Language by ear and
Mass: M.I.T. Press, 1972. Pp. 159-192.

Shankweiler. D.. \& Liberman, I. Y. Misreading: A search for causes. In J. F. Kavanaugh and I. G. Mattingly (Eds.), Language by ear and by eye. Cambridge, Mass: M.I.T. Press, 1972. Pp. 293-318.

\section{NOTE}

1. Mackworth. J. F.. \& Mackworth. N. H. How children read: Matching by sight and by sound. In preparation.

(Received for publication October 9. 1973.) 